\title{
ADVANCING THE CIRCULAR ECONOMY THROUGH GROUP DECISION-MAKING AND STAKEHOLDER INVOLVEMENT
}

\author{
John Bachér *, Hanna Pihkola, Lauri Kujanpää and Ulla-M. Mroueh \\ VTT Technical Research Centre of Finland, Biologinkuja 7, 02150 Espoo, Finland
}

Article Info:

Received:

26 January 2018

Revised:

5 September 2018

Accepted:

31 October 2018

Available online:

23 November 2018

Keywords:

Multicriteria analysis

Group decision-making

Circular economy

End-of-life vehicles

Plastic packaging waste

Value chain

\begin{abstract}
This paper discusses the potential of Multicriteria Decision-Making Methods (MCDM) to support co-operation between stakeholders and the ability to tackle bottlenecks in the recycling value chains. The empirical part of the paper is based on two MCDM exercises in which bottlenecks that hinder the efficient recycling of end-of-life vehicles and plastic packaging waste were evaluated and prioritized. The interlinked nature of the recycling chains poses challenges for the application of MCDM methods, and studies that apply group decision-making in the context of the circular economy are still rare. Despite these challenges, the findings of our case study indicate that group decision-making methods could be applied as participatory methods to enable the collection and integration of stakeholder views within circular economy policy development and implementation activities. A review of literature on existing bottlenecks for the circular economy indicates that there is an increasing need for co-operation and knowledge exchange between actors. It is proposed that in the future, MCDM methods could be used to create joint learning and idea exchange between value chain actors, as these are considered necessary for advancing the circular economy.
\end{abstract}

\section{INTRODUCTION}

A key priority of the EU Circular Economy Action Plan is improving resource efficiency in the EU. The move towards a circular economy (CE) requires integrating life cycle thinking in product design and all subsequent life cycle stages in order to enable efficient recycling, recovery, repair and re-use (European Commission, 2015). The basic principles of the circular economy include creating economic growth and increasing the well-being of people, while reducing resource use and greenhouse gas emissions, and operating within the planetary boundaries (European Commission, 2015).

However, several barriers hindering the transition towards a CE have been identified. These barriers are diverse and include technical, economic, institutional and social aspects (de Jesus and Mendonça 2018). According to Preston (2012), barriers to implementing CE include inter alia failures in company co-operation and limited dissemination of innovation. Other review studies mention information deficits (Rizos et al., 2015), minor consumer and business acceptance and a lack of awareness and information (Vanner et al., 2014) as the main barriers to CE.

Since the recycling chain consists of a series of processes handled by different actors, finding potential solutions to circular economy challenges requires co-operation along the value chain (Bacher et al., 2016). From a policy maker's perspective, transition towards a CE therefore may require balancing between trade-offs in economic, social and environmental sustainability related to material recycling and potential conflicts in stakeholder interests.

Methods for Multicriteria Decision-Making (MCDM) have been developed to help decision-makers to identify and select preferred alternatives when faced with a complex decision problem that is characterized by multiple objectives (Seppälä et al., 2002). In the context of the circular economy, MCDM methods could provide potential means for prioritising policy options and alternative implementation routes, which take into account the views of various stakeholders who are affected by the policies and who are in a key position to advance the circular economy. This paper discusses the potential of structured group decision-making methods to support cooperation between stakeholders and create learning that would be necessary in order to tackle the bottlenecks faced in the recycling value chains. The empirical part of the paper is based on two MCDM exercises in which bottlenecks that hinder efficient recycling of end-of-life vehicles and plastic packaging waste were evaluated and prioritized.

Previously, MCDM methods have been used in the context of waste management, especially for selecting preferable waste management strategies and locations (Goulart Coelho et al., 2017; Morrissey and Browne, 2004; Rousis et 
al., 2008; Soltani et al., 2015). According to a review of 68 studies by Soltani et al., (2015), the number of MCDM studies incorporating group decision-making has significantly increased during the past decade while less attention has been given to the interaction between the stakeholders involved. The importance of the latter arises from the diverse and conflicting interests of the decision-makers involved, which makes reaching an agreement challenging. Indeed, depending on the hierarchy and competitive positions of the stakeholders, each decision-maker considers the decisions of others on top of their own preferences.

Involving multiple stakeholders in shared decision-making can have a positive impact on the results. Van den Hove (2006) stated that participatory approaches in the current MCDM methods increase the transparency and fairness of the results. In addition to building consensus, MCDM methods can be used to highlight the diverse interests of the participating stakeholders (Kiker et al., 2005). In a participatory process, understanding the differences in opinions and preferences may be as important as reaching consensus.

The approach presented in this paper differs from earlier studies, since the aim of the MCDM exercises was to enable more efficient recycling and circular use of resources, by evaluating the bottlenecks identified within the value chains. By prioritising the bottlenecks, future policy and research actions could be targeted to activities which would lead to the most positive impacts in the whole value chain.Thus, the focus of the studies is not only on the end of the life cycle (for example in selecting a preferred waste management system or facility location), but also on the life cycle as a whole, since the bottlenecks were located in different parts of the life cycle.

The use of MCDM methods in the context of circular economy studies is still rare, even though the amount of literature discussing CE is growing rapidly. Thus, our case study brings an additional contribution to the expanding CE research, by applying MCMD methods within the context of two recycling value chains, and it focuses the assessment on the level of a supply chain. In their analysis of altogether 565 CE related journal articles, Merli et al., (2018) found that the majority of the papers the evaluated were modelling studies and case studies, and that the methods most commonly applied included Life Cycle Assessment (LCA) and Material Flow Analysis (MFA) types of methods. Almost half of the studies analyzed belonged to the category "Tools, models, framework and methods for decision-making, consisting of studies developing theoretical or empirical instruments and approaches to evaluate and develop CE (Merli et al., 2018). Interestingly, MCDM methods were not mentioned among the applied methods, although providing decision support for evaluating and developing the circular economy was a popular theme. Another finding was that most CE studies were focused on the macro-level (society, country) or on the micro-level (corporate and/or consumer level), and only a small number was focused on a supply chain in which more firms would be involved (Merli et al., 2018).

While potential barriers and success factors related to CE concepts have been studied on several occasions (for a review see, e.g. Winans et al., 2017), participatory, group decision-making methods have not been used in this context. Mahpour (2018) used a similar approach and applied a MCDM method (fuzzy topis) for prioritising barriers for adopting circular economy in construction and demolition waste management. However, in this exercise, expert opinions were collected using a survey, and thus the interaction between the experts was not included in the study. Zhao et al., (2017) used a hybrid MCDM approach to evaluate and rank potential environmental, economic and social benefits of eco-industrial parks in China. In their study, expert opinions were used to build an evaluation index system based on evaluations collected from experts representing several different fields. Also in this context, expert opinions were collected using questionnaires instead of group decision-making.

Thus, the main contribution and novelty value of this paper is to discuss potential benefits and challenges when applying group decision-making methods in the context of circular economy problem solving. The paper is structured as follows: Chapter 2 describes the case study and the evaluated value chains. Chapter 3 presents the applied MCDM approach and explains how the empirical case study was conducted in practice. Chapter 4 presents the case study results and related learnings, together with the considerations related to the limitations of the study. Conclusions are presented in Chapter 5 together with the potential policy implications and recommendations, which are considered as the main contribution of this study.

\section{CASE DESCRIPTION}

\subsection{Introduction and context}

The empirical part of the paper is based on a case study in which group decision-making methods were applied to evaluate and prioritize bottlenecks within two recycling value chains: End-of-Life Vehicles (ELV) and Plastics Packaging Waste (PPW). Identification of the bottlenecks was conducted in the context of a recent EU Horizon 2020 project NEW_InnoNet. In the project, two different value chains were selected in order to understand whether the bottlenecks were specific to a waste stream or whether there were commonalities between the value chains, and consequently, if some uniform solutions could be found which might help in solving the challenges faced in the recycling chains in general, despite the waste stream.

Bottlenecks were defined as factors that limit the performance and efficiency of the value chain and thus prevent or limit the move towards a near zero-waste value chain and circular economy. As part of the study, expert workshops were organized to discuss and prioritize the bottlenecks in the evaluated value chains. In the workshops, structured group decision-making methods were applied.

\subsection{Evaluated value chains: End-of-life vehicles and Plastic packaging waste}

MCDM exercises were carried out for two recycling value chains: End-of-life vehicle (ELV) and plastic packaging waste (PPW). In Europe both of these waste streams 
are under the Extended Producer Responsibility (EPR) schemes which govern the end-of-life management through the ELV and PPW directives (Directive 94/62/EC; Directive 2000/53/EC). In general terms, value chains comprise actors that perform operations to deliver valuable concentrates/products or services to the market. Within the context of recycling and waste management, the value chain begins at the point where the consumer discards the product thus creating waste. Furthermore, if reuse is not possible, due to the loss of functionality, the theoretical value potential of waste equals the value of material. This drives the recycling industry together with increasing disposal costs, increased public concern about the health and environmental impacts of waste disposal as well as the fear of future scarcity of certain natural resources to separate valuable materials and concentrates for the refining industry for element recovery and refining (van Beukering et al., 2014). Commonly, the value chain ends at the point where material is semi-finished goods. A schematic description of a general recycling value chain is presented in Figure 1.

Typically, the first operation after discarding the product is collection, which aims at collecting maximal amount of waste to be treated properly. This step is realized by waste management companies and different collection points. In order to meet the requirements of EPR schemes, manufacturers commonly establish Producer Responsibility Organizations (PRO) which are responsible for taking back used goods and for sorting and treating for their eventual recycling (Monier et al., 2014). However, in practice PROs may purchase the collection from a third party such as a waste management company. Collection methods vary between the waste streams. For PPW it can be arranged by separate collection, deposit system, kerbside collection or at various collection points (da Cruz et al., 2014; Dahlbo et al., 2018; Groot et al., 2014; Hahladakis et al., 2018). For ELVs, the collection is often managed by specific collection points. During the ELV collection, a depollution step is usually carried out to remove fluids, tyres, batteries and other possible hazardous components which are required by the ELV directive (Directive 2000/53/EC).

After collection, sorting and mechanical treatment are carried out to separate possible components/parts for reuse and to separate valuable materials which can be different metals in the ELV value chain and different plastic types for the PPW chain for further refining as well as removing harmful components for proper disposal (Inghels et al., 2016; Shen and Worrell, 2014). Especially for the ELV value chain, parts or components may be removed for reuse or separate treatment prior to the shredding process (Andersson et al., 2017a; Inghels et al., 2016). Commonly, recycling companies are responsible for this stage. Finally, valuable concentrates from ELV recyclers are refined for intermediate products such as steel billets for the manufacturing industry. In metals production, different smelters and metallurgical companies carry out the refining (Andersson et al., 2017a). In plastics production refining includes melting or processing which is conducted by plastic converters (Shen and Worrell, 2014). In Table 1, a summary of typical characteristics of ELV and PPW streams is presented.

The nature of ELV and PPW differ significantly, especially considering the average product size and lifespan (Table 1). In addition, material composition of the waste stream is different. This together with the waste generation affects

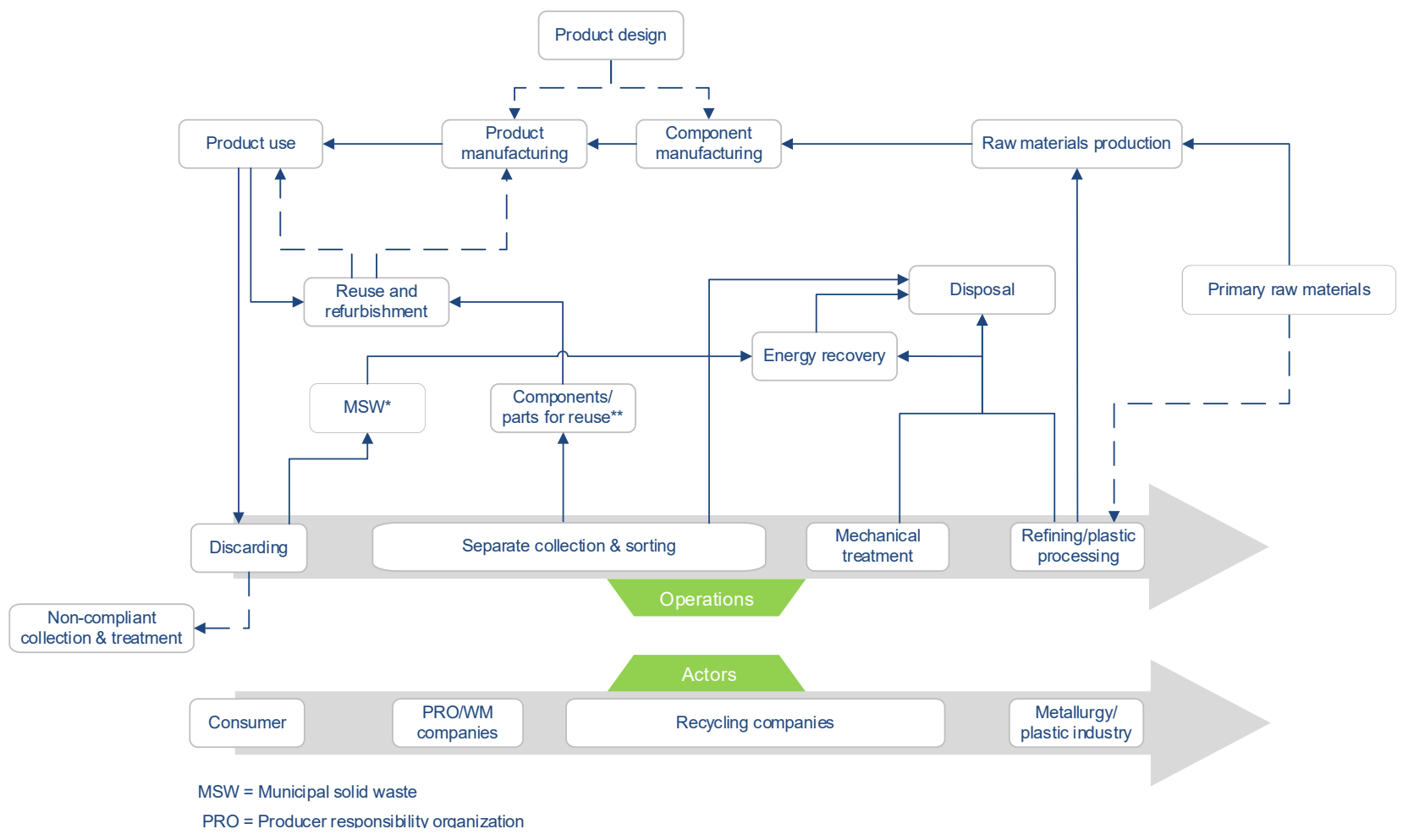

FIGURE 1: Overall description of a value chain within the recycling context. 
TABLE 1: Typical characteristics of ELV and PPW value chains. (Directive 94/62/EC; Directive 2000/53/EC; Geyer et al. 2017; Eurostat, 2018a; Eurostat, 2018b; Inghels et al., 2016; Worrell, 2014).

\begin{tabular}{|c|c|c|}
\hline Feature & ELV & PPW \\
\hline Quantity (Mt/year) 2009-2015 & $6-8$ & $14.5-16$ \\
\hline Rough composition & $\begin{array}{l}\text { Metals, plastics (different type), glass, wood, minerals, } \\
\text { rubber, fluids, others }\end{array}$ & $\begin{array}{l}\text { Mainly different type of plastics (PET, HDPE, PP, PVC), } \\
\text { but may contain in small quantities other materials and } \\
\text { residuals }\end{array}$ \\
\hline Collection method & Specific collection points & Separate and mixed collection, refund, drop-off, curbside \\
\hline Current recycling rate in 2015 (\%) & $87.1^{+}$ & $40.2^{+}$ \\
\hline Recycling rate target (\%) & 85 * & 55 ** \\
\hline Typical product size & Hundreds of kilograms & Below one kilogram \\
\hline Average lifespan of the product & Over10 years & Below one year \\
\hline
\end{tabular}

the value chain actors and their operations. It should be noted that the waste generation quantities in Table 1 are based on statistical data that does not take into account emerging quantities outside official monitoring. By looking at recycling rate targets, beside the high metal content of cars, the long history of ELV recycling (Andersson et al., $2017 \mathrm{~b})$ reflects in the high recycling rate targets compared with the PPW which has gained attention only during the last decade.

Despite the current relatively high recycling rate for ELV, complex vehicle design integrating materials together and the increasing share of light materials generate challenges for current and future recycling (Soo et al., 2017). On the other hand, increasing valuable and scarce metal concentrations due to electrification of vehicles generate opportunities for recycling scarce metals that are currently lost (Andersson et al., 2017a). To further increase the recycling rate in the PPW chain, key challenges include reaching better quality recycled materials despite the complexity of the input materials. This can be achieved through good integration of collection, recovery and separation technology (Shen and Worrell, 2014).

\subsection{Bottlenecks identified in the value chains}

Industrial experts and researchers identified the bottlenecks within the value chains prior to the prioritization exercises. The bottlenecks that hinder or limit the transition towards a zero waste society and circular economy were both technical and non-technical (financial, organizational, political, legal or societal) in nature. Further, they affected several points of the value chain. Altogether 10 bottlenecks were identified within the PPW chain, and 15 within the ELV chain. All the bottlenecks were presented and discussed during the expert panel workshops, and participating experts acknowledged the existence of these bottlenecks. However, due to the lack of background data and availability of measured information on the potential impact of bottleneck removal, only 5 out of 10 identified bottlenecks in the PPW chain and 5 out of 15 identified bottlenecks in the ELV chain could be evaluated within the MCDM exercise. In Table 2, bottlenecks that were included within the prioritization using MCDM are presented with a short description. Excluded bottlenecks are listed below the table.
Bottlenecks identified in the PPW value chain but excluded from the prioritization were:

- Lack of common calculation methodology to calculate EU recycling targets, including more measuring points (collection, sorting and recycling) to efficiently measure the material flow;

- Supply of highly heterogeneous and/or contaminated plastics from collection leading to downcycling and high rejection rates;

- Lack of market trust in products containing recycled plastics; absence of quality requirement (end of waste criteria) for recycled plastic waste, on both the supply and demand side;

- Product standards limiting the use of recycled material

- Uneven playing field for environmentally sound recycling plants because of non harmonized EU legislation in Member States and regions.

Bottlenecks identified in the ELV value chain but excluded from the prioritization were:

- Lack of accreditation and standardization for ELV recycling operators;

- Counterproductive regulation prohibiting improving recycling;

- Lack of Europe-wide harmonization in regulation, poor governance and ineffective enforcement of regulation;

- presence of unwanted substances prohibiting further qualitative application;

- Secondary material pricing is benchmarked against primary material pricing;

- Rapidly changing vehicle designs (model updates), technical compositions and higher contributions of consumers in vehicle design;

- Transportability of goods and materials - High share of small regionally operating companies in the vehicle end-of-life chain;

- Lack of stability (volume/economic) in secondary material supply chain is not motivational for material producers to integrate recycled streams;

- No incentive for manufacturers to develop recyclable products, as vehicle use emissions are dominant design choice in total environmental performance; 
TABLE 2: Bottlenecks included in the priorization exercise. (Bacher et al., 2016).

\begin{tabular}{|c|c|c|}
\hline Waste stream & Bottleneck & Description \\
\hline PPW & $\begin{array}{l}\text { Limited source separation of } \\
\text { plastic packaging waste }\end{array}$ & $\begin{array}{l}\text { No or inappropriate systems for source separation of plastic packaging are in place. Recyclable plas- } \\
\text { tics end up in residual waste stream and are diverted to the corresponding treatments (disposal/ } \\
\text { incineration). }\end{array}$ \\
\hline PPW & 'Bad' product design & $\begin{array}{l}\text { Product design and use of composite materials are not adapted to current technologies for sorting/ } \\
\text { separating materials. This results in plastics technically or economically not fit for recycling, leading to } \\
\text { loss of material value and decreased yield in pre-treatment. }\end{array}$ \\
\hline PPW & $\begin{array}{l}\text { Export of plastic packaging } \\
\text { waste for recycling outside EU }\end{array}$ & $\begin{array}{l}\text { Lower costs for recycling (because of lower human and environmental standards) causes export of } \\
\text { plastic waste. The potential to create benefits from recycling is consequently reduced in the EU. }\end{array}$ \\
\hline PPW & $\begin{array}{l}\text { Performance of separation / } \\
\text { sorting technology }\end{array}$ & $\begin{array}{l}\text { Part of the plastic packaging waste ends up in disposal or incineration due to technology not being } \\
\text { able to sort new packaging product designs. The root causes are presence of unwanted substances in } \\
\text { the plastic waste streams, high cost for removing them and finally product development going faster } \\
\text { than the recycling technology development. }\end{array}$ \\
\hline PPW & $\begin{array}{l}\text { Performance of recycling } \\
\text { technology }\end{array}$ & $\begin{array}{l}\text { Part of the plastic packaging waste is ending up in disposal or incineration due to slow development } \\
\text { in the recycling technology, reducing the yield of recycling. }\end{array}$ \\
\hline ELV & $\begin{array}{l}\text { Inadequate performance of the } \\
\text { separation, sorting and refining } \\
\text { technology }\end{array}$ & $\begin{array}{l}\text { Vehicle (material) innovation in the construction phase leads to higher levels of intermingled, alloyed } \\
\text { and glued material particles. New components are required to be lighter by weight, but with similar } \\
\text { or better operational performance. In the current recycling system, this leads to a higher degree of } \\
\text { materials with overlapping properties }\end{array}$ \\
\hline ELV & $\begin{array}{l}\text { Inadequate performance of } \\
\text { vehicle dismantling and reuse } \\
\text { application }\end{array}$ & $\begin{array}{l}\text { Construction complexity and smart connected parts leads to higher effort required to dismantle com- } \\
\text { ponents for a reuse application. High-voltage components require more safety measures by the col- } \\
\text { lection and dismantling chain. The opportunity to dismantle parts for material recycling decreases as } \\
\text { intrinsic material value is depleted }\end{array}$ \\
\hline ELV & $\begin{array}{l}\text { Limited and low quality applica- } \\
\text { tion outlets of non-metallic ELV } \\
\text { materials }\end{array}$ & $\begin{array}{l}\text { Economic and technical feasibility to sort, separate and refine non-metallics is low due to the hetero- } \\
\text { geneous composition of 'shredder output'. Materials are sorted, and due to their low economic value, } \\
\text { can only be recycled in low-grade applications }\end{array}$ \\
\hline ELV & $\begin{array}{l}\text { Inadequate performance of ELV } \\
\text { collection and monitoring }\end{array}$ & $\begin{array}{l}\text { Interpretation of what actually an ELV is, how it should be recycled and how the recycling sub quota } \\
\text { should be monitored and judged depend on many factors. This creates unclarity for stakeholders and } \\
\text { provides incentives for substandard treatment. It further results in a lack of reliable data availability on } \\
\text { vehicle registration and composition, ELV arising and vehicle / ELV trade }\end{array}$ \\
\hline ELV & $\begin{array}{l}\text { Low-cost of energy recovery } \\
\text { and landfilling alternatives } \\
\text { compared to material recovery }\end{array}$ & $\begin{array}{l}\text { In some EU Member States, overcapacities (and competition) in incineration facilities and landfill } \\
\text { deposits, as well as low taxation rates, lead to low gate fees. This creates an uneven playing field } \\
\text { compared to material recycling, of which the operational costs are usually higher than for incineration } \\
\text { and disposal. }\end{array}$ \\
\hline
\end{tabular}

- Total arising from ELVs is dropping and ageing, due to 'fewer accidents', higher safety measures and vehicle exports to foreign destinations (outside the EU).

The bottlenecks included in the MCDM were selected based on the ability to measure their potential impacts in quantitative terms. This was considered as a limitation, but the participants approved the decision. Practical and methodological reasons for excluding part of the bottlenecks and reducing the applied evaluation criteria are further discussed in Chapters 3 and 4.

\section{MATERIALS AND METHODS}

\subsection{Applied MCDM methods}

The ability of MCDM methods to produce viable results is based on breaking down complex problems into manageable components, which usually are, as reviewed by Goulart Coelho et al., (2017), (i) goal and scope definition; (ii) theoretical framework definition; (iii) criteria and indicators selection; (iv) data normalization; (v) weighing attribution, and (vi) sensitivity analysis. When applied for group decision-making, MCDM can be used to highlight the similarities and potential causes of conflicts between stakeholder views, and thus improve a shared understanding of the problem (Kiker et al., 2005).

There are many different systematic MCDM methods available for evaluating alternatives based on multiple criteria. However, they often share a similar approach to structuring the decision problem into a set of alternatives and a goal that can be divided into non-redundant lower level objectives and related criteria (Kiker et al., 2005). Consequently, a matrix of alternatives and their performances in each criterion can be created (Figure 2). MCDM methods (for problems where an alternative needs to be selected or ranked) can be divided into value-based, outranking-based or reference-based methods (Goulart Coelho et al., 2017). The value-based methods produce a single aggregated numerical score for each alternative on a cardinal scale, while outranking methods aim to compensate for less easily measured criteria performances by indicating the extent of how much an alternative dominates another (Kiker et al., 2005). Reference-based methods indicate the best or worst alternative by measuring their distance to an ideal or worst possible solution (Goulart Coelho et al., 2017).

Two value-based methods, the Analytic Hierarchy Process (AHP) (Saaty, 1980) and Multi-Attribute Utility and Value Theories (MAUT/MAVT) (Dyer and Sarin, 1979; Keeney and Raiffa, 1994) were used in this study. According to a recent review by Soltani et al., (2015), the Analytic Hierarchy Process (AHP) (Saaty, 1980) was by far the most commonly used MCDM method in waste management studies involving multiple stakeholders, followed the by outranking methods PROMETHEE and ELECTRE and the reference level model TOPSIS. Contrary to the preceding, however, Goulart Coelho et al., (2017) reported in their review study that the Multi-Attribute Utility and Value Theories (MAUT/ MAVT) (Dyer and Sarin, 1979; Keeney and Raiffa, 1994) were the second most common MCDM methods in waste 
management studies. The most common usage of AHP and MAUT/MAVT in the studies reviewed by Goulart Coelho et al., (2017) was the selection of a facility location. Both MAVT and AHP are optimization methods that produce an aggregated overall numerical score of each alternative in a single cardinal scale (Kiker et al., 2005).

In the case study, both MCDM exercises were carried out as group exercises during a two-day expert panel workshop. The time available for group discussions and reaching consensus, together with the availability of background data affected the selection of the MCDM methods.

For the plastic packaging value chain, MAVT was chosen due to availability of detailed numerical data on the bottleneck performances in a defined set of criteria. In MAVT, the Decision Maker's (DM's) preferences are modelled as value functions and their weights (Equation 1). A value function $v_{i}^{N}\left(x_{i}\right)$ transforms any measured variable $x_{i}$ to a number representing its subjective value for the DM. The value functions $v_{i}^{N}\left(x_{i}\right)$ were assumed linear in the study, as their detailed elicitation was judged too time-consuming for the time and resources available.

According to MAVT, the overall value of an alternative is calculated using the additive value function:

$V(x)=\sum_{i=1}^{n} w_{i} v_{i}^{N}\left(x_{i}\right)$

Where:

$V(x)$ is the overall value of an alternative,

$v_{i}^{N}\left(x_{i}\right)$ is the normalized value of a criterion performance of an alternative and

$w_{i}$ is a weight given for a criterion.

$v_{i}^{N}\left(x_{i}^{0}\right)=0$

and

$v_{i}^{N}\left(x_{i}^{*}\right)=1$

apply for the normalized value functions. $x_{i}^{0}$ equals the worst and $x_{i}^{*}$ the best performance level for each criterion (in Equations 2 and 3 ).
Criterion weight $w_{i}$ reflects the increase in overall value when the criterion performance is changed from the worst level $x_{i}^{0}$ to the best $x_{i}^{*}$. The following equation applies for the criteria weights (Equation 4):

$\sum_{i=1}^{n} w_{i}=1$

The weights $w_{i}$ were taken as averages of the individual DM's answers during the Expert Panel Workshops (EPWs). The DMs' preferences were elicited using trade-off weighing. The DMs were asked to compare the best possible performance in each criterion against an equally valued hypothetical performance in the most important criterion. Before presenting the trade-off questions, the most important criterion was selected as a shared decision by the expert panel.

Less data was available in the ELV value chain on the criteria performances of the bottlenecks, thus demanding expert judgement during the EPWs. Consequently, the AHP method was applied to ELV value chain in order to prioritize the identified bottlenecks. In AHP, a DM forms local priorities by comparing the importance of each same level elements (alternatives or criteria) against each other regarding each element on the next level upwards (lower levels objectives or the main objective). In the EPW on the ELV value chain, the DMs were first asked to compare the importance of each criterion in achieving the goal. Once this was done, all the alternatives (bottlenecks) were compared against each other regarding their performances in each criterion. The fundamental scale from 1 (equally important) to 9 (extremely more important) presented by Saaty (1980) was used in the comparison of same level elements.

\subsection{Selection of the expert panel and organization of the decision-making exercises}

Invitations to the workshop were sent to selected experts and organizations active within the case value chains and acknowledged by the project partners. Therefore, the input to the case study was obtained by non-ran-

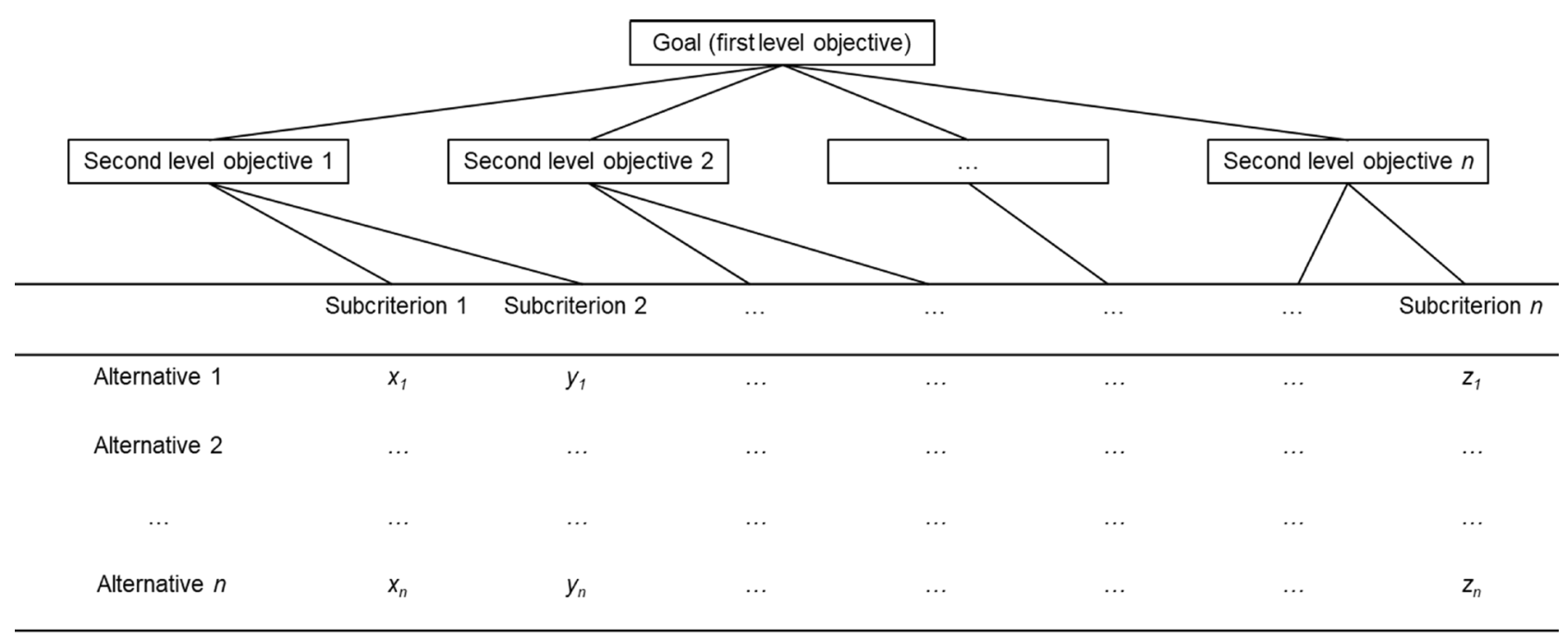

FIGURE 2: A generic example of a structured decision problem with alternatives evaluated by performances in multiple criteria. 
dom expert sampling. Experts from universities, recyclers, car manufacturers, environmental protection agencies and both automobile producer and importer agencies were contacted for participation in the ELV workshop. Experts for the PPW workshop were invited from public waste agencies, plastic recyclers and polymer producers, ministries and research institutes. Project partners, including experts who were involved in the bottleneck analysis, definition of the theoretical framework, criteria and indicators or data collection were not included in the expert panels. The workflow of the EPWs is presented in Figure 3.

Firstly, the value chain and the objective of the MCDM were presented to the expert panel members. Once a necessary understanding of the decision problem and the system boundaries was reached, the decision alternatives (bottlenecks) were presented to the panel members. This was followed by an interpretation of the decision criteria, where the criteria measures' definitions were revisited in order to direct the group of experts towards making comparable decisions. The material on the value chain, MCDM goal and criteria and the bottlenecks was also given to the invited expert panel members before the workshop. Making sure that all participants understood the applied criteria and parameters was necessary so that the model would really be in line with preferences of the decision-makers and that the calculations produced priorities that really represent their preferences (Kangas et al., 2001).

After ensuring all the expert panel members were sufficiently informed and sharing the same ground about the decision-making problem, the actual elicitation of preferences was begun on the second day of the workshops using the appropriate MCDM method, AHP (ELV value chain) or

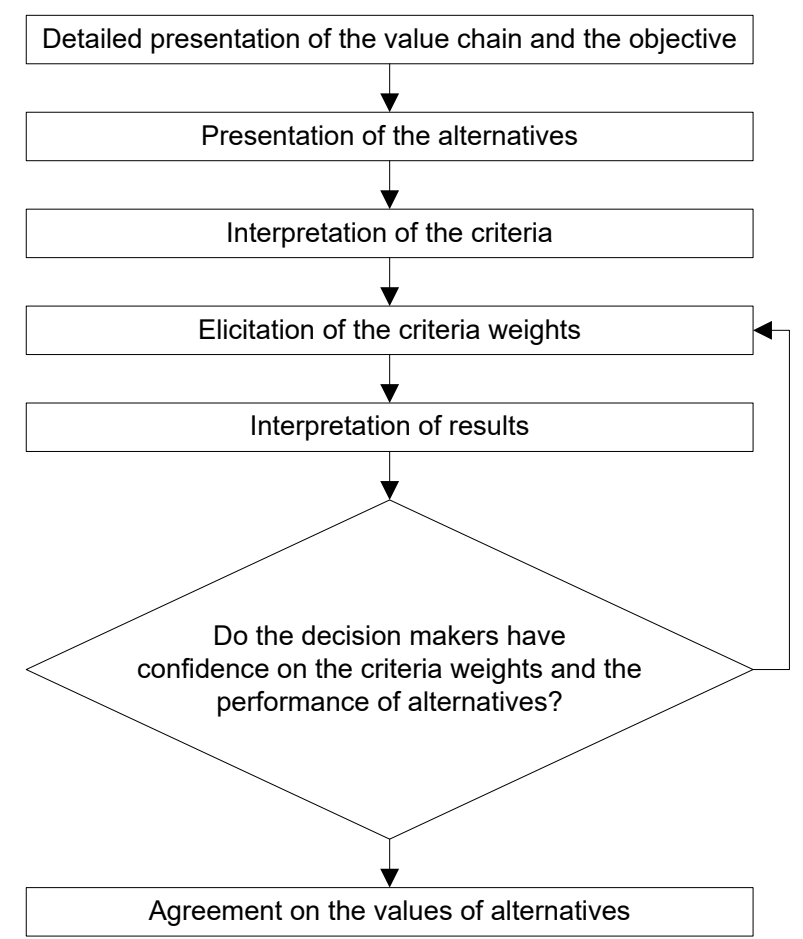

FIGURE 3: Workflow of bottleneck prioritization in expert panel workshops using Multiple Criteria Decision Making (MCDM).
MAVT (plastic packaging value chain). The resulting criteria weights and performances of the alternatives were subsequently combined to determine the preference order of alternatives. The results were presented to the expert panel to consider whether their preferences indeed were aligned with the final criteria weights and the priority order of the alternatives. An option to make correcting value statements was given to the individual panel members to ensure an agreement on the final priority order of the alternatives.

The expert panel in the plastics value chain consisted of three DMs during the elicitation of the criteria weights. The affiliations of the experts were to a waste recycling company, a national environment institute and an EU-level trade association.

Eight experts participated to the elicitation of weights for the selected evaluation criteria in the ELV value chain. The participants included representatives of companies working in the ELV value chain, related interest groups and associations and researchers working within the field of ELV. Due to time limitations, the elicitation of the bottleneck performances in each criteria of the ELV value chain was conducted after the workshop via an electronic questionnaire sent to all workshop participants. Six of the experts completed the survey and thus participated in prioritizing the bottlenecks. The joint findings from the workshop and the questionnaire were sent to all respondents for information and comments.

\subsection{The evaluation criteria for the bottlenecks}

The goal of the MCDM was to establish the priority order of the bottlenecks to be removed based on their impact on the transition toward a circular economy. The interpretation of the goal and its division into suitable non-redundant criteria was done by the project group. The criteria defined during the planning stage before the value chain analysis covered the economic, environmental and material efficiency effects of the bottlenecks, as these were considered important lower level objectives.

During the identification of bottlenecks and later on in the discussions during the decision making exercise, vague definitions of circular economy and its relation to the zero waste concept were highlighted. Both concepts were discussed and considered to represent similar objectives. At the time of the workshop, the final version of the EU Action Plan for the Circular Economy was not yet available, and thus no official European definition was available. During the discussion with the experts, the move towards a zero waste society was seen as a more concrete definition and goal, and practical for the purposes of the MCDM. Participating experts agreed that a zero waste society aims at promoting the realization of the waste hierarchy (prevention, reuse, recycling, recovery and disposal) to minimize and reduce waste throughout the life cycle of an application. Overall, removing bottlenecks for recycling was considered important in any case, whether the overall goal would refer to a zero waste society or to a circular economy.

In order to carry out the MCDM, the effect of bottleneck removal on the entire value chain had to be assessed. This was found challenging, as information of the material flows within the recycling chains on the European level 
is inadequate, and total amounts of materials that end up outside the recycling chains are not known. Consequently, many assumptions had to be made and a lot of uncertainty was related to the data and the applied parameter values. However, coping with uncertainty is typical for the MCDM situations and has to be taken into account when conducting a sensitivity analysis and analyzing the results (Kangas et al., 2001).

Within the PPW chain, the effect of bottleneck removal was evaluated based on data available from the literature, and the information was shared in advance with experts who participated in the group decision-making.

The criteria included within the assessment of the PPW chain were:

- Losses of plastics in the recycling system;

- Total EU cost of the recycling scenario per ton recycled plastic packaging waste;

- Total EU revenues of the recycling scenario per ton recycled plastic packaging waste;

- Total of GHG emissions inside the EU due to the recycling scenario per ton waste generated;

- Employment (Jobs/ton recycled);

- Employment (Total jobs);

- Feasibility.

In the ELV chain, the evaluation of importance of the bottleneck removal was carried out by expert panel members based on their own expertise due to the lack of background data. Due to lack of data, also the number of criteria that could be included within the assessment of the ELV chain was reduced and only criteria referring to material savings potential and cost of recycling could be included. The expert panel members formulated the final definition of the criteria for ELV as part of the workshop.

The criteria included within the assessment of the ELV chain were:

- Reducing losses of plastics;

- Reducing losses of ferrous metals;

Reducing losses of non-ferrous metals;

- Reducing cost of recycling.

\section{RESULTS AND DISCUSSION}

The results from the MCDM consist of criteria weightings and the final prioritization of the bottlenecks in the evaluated value chains. Chapter 4.1 presents the results for the plastics packaging chain and Chapter 4.2 the endof-life vehicles chain. Experiences and learnings from the two cases are discussed in Chapter 4.3, as these are considered important for evaluating the applicability of the MCDM methods in this kind of problem solving. The final part of the chapter (Chapter 4.4) considers the limitations of the study and their impact on the results and their usability.

\subsection{Priorization of bottlenecks within the plastic packaging value chain}

The expert panel selected "Losses of plastics" in the PPW recycling system as the most important criterion (Fig- ure 4). Regardless of the critique expressed on the spatial scope of the criteria, "GHG gas emissions within EU" was judged as the second most important criterion. The weights of these two criteria were clearly distinguished from the rest of the criteria. Even more clearly distinguished was the "Employment per recycled amount of plastic" (jobs/ton recycled) which was by far the least valued criterion.

The results show (see Figure 5) that solving the "Limited source separation" of plastic packaging waste would provide most value from among the bottlenecks. This is due to good performance in creating jobs, reducing GHG emissions within the EU, reducing costs per recycled plastic and most of all, reducing the losses of plastics in the recycling system. The value of prioritizing the solving of limited source separation was roughly three times the value of the next most valued alternative, "Improving the performance of separation/sorting technology". "Improving the performance of recycling technology" came third, followed by limiting the "Export of plastic packaging waste" and improving recyclability in the "Product design phase". Of all the alternatives, "Improving the performance of separation, sorting and recycling technologies" had the best feasibility values among the alternatives. In other words, they were judged as the alternatives being the most ready for implementation.

The expert panel, when presented with the criteria weights and total values of the alternatives, were quite content with how their views were translated to the results. The panel members asked to make only minor adjustments to their elicitation answers, and especially the effect of giving more or less value to the feasibility was tested. However, the priority order of the bottleneck remained.

\subsection{Priorization of bottlenecks within the ELV value chain}

In the ELV workshop, "Cost of recycling" gained highest weight whereas "Losses of Fe-metals" was ranked as the least important criterion (Figure 6). "Losses of non-Fe metals" was seen as the second most important criterion with a rather significant weight. The weight of "Losses of plastics" criterion was notably lower than for the first two, but was still considered more important than "Losses of Fe metals". In the discussion of the results between experts, the results did not come as a surprise and actually represented rather well the overall impression of the situation.

The outcome of the weighting was a result of the joint discussions during the workshop, and based on the interpretations on the available information. Thus, in practice, the answers given by the experts and consequently the results are dependent on the situation, and would vary in time.

The AHP highlighted (Figure 7) "Inadequate performance of vehicle dismantling and reuse application" as the most valued decision alternative of the five bottlenecks analyzed. However, "Inadequate performance of the separation, sorting and refining technology" as well as "Inadequate performance of ELV collection and monitoring" were valued nearly as strongly as the first one. The remaining two bottlenecks of qualitative nature gained clearly lower importance than the three technical ones. A possible reason for this is that the defining and quantifying of these two 


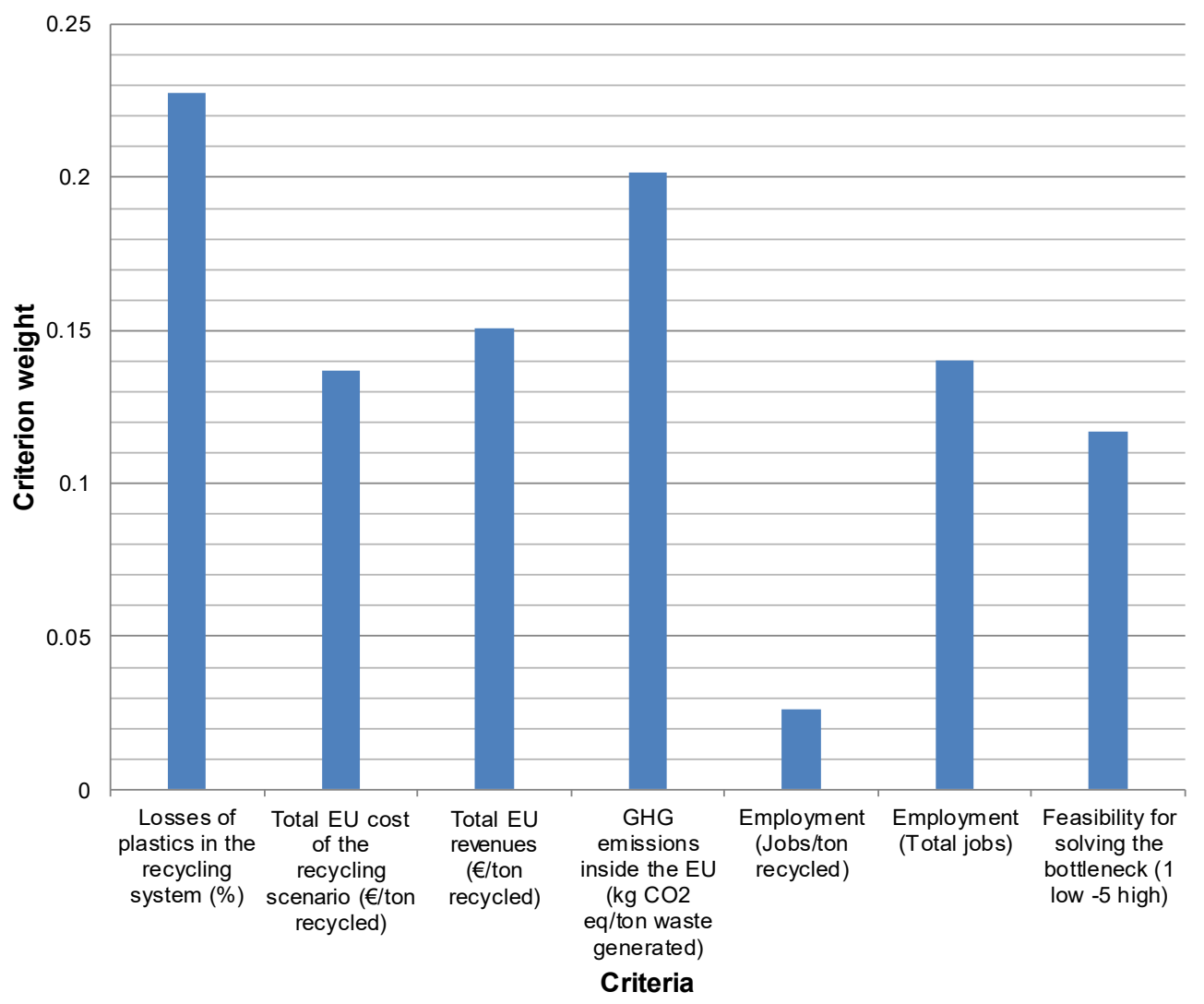

FIGURE 4: The criteria weights in the PPW chain. Adapted from (Bacher et al., 2016).

bottlenecks and their effects are more challenging which may have been reflected in the answers of the experts.

The answers received from the experts varied significantly, and this may at least partly depend of the background of the respondents. Commonly the background of an expert seemed to reflect the importance of the bottleneck. Therefore, it is important to have experts in the analysis from all stages of the value chain. In addition, a broader spectrum of the fields (academic, industry, etc.) of the experts would better take into account both the theoretical and practical point of views.

\subsection{Discussion: Learnings from the case study}

Despite the differences in the material compositions of the evaluated value chains, many similarities between the value chains and bottlenecks were identified. For example, among the important aspects were costs of recycling, unstable demand and low prices of the recovered materials (other than metals). Additionally, many of the bottlenecks related to the heterogenic composition of the input material that presents challenges for recovery and refining of the materials. Although recyclers have limited ability to affect product design, creating guidelines for product manufacturers and designers for taking into account the demands of material recycling could be an effective means in moving towards the more efficient and sustainable use of resources (Bacher et al., 2016). The importance of product design for improving recycling efficiencies underlines the need for a lifecycle approach that is central within the circular economy concept.

Due to the value chain focus and interlinked nature of the bottlenecks, evaluating their impacts within the value chains was rather difficult for the experts who participated in the workshops. Other challenges related to unclear definitions. Recent studies point out that the circular economy is a rapidly evolving concept and common agreements on necessary guiding principles for action are still missing (Merli et al., 2018). This highlights the importance of the goal definition for the MCDM, as it has to be clear for all participating experts. In the case of a blurred concept like the circular economy, a more case-specific definition of the circular economy should be created, including potential environmental, economic and social impacts.

Further challenges in applying the MCDM method in practice included lack of data related to the value chains, definition of comprehensive criteria that would be able to cover relevant economic, environmental and social aspects in quantitative terms, and engaging a balanced group of stakeholder representatives in the MCDM exercises. Since the bottlenecks were located along the value chain, there was a need for detailed economic, environmental and social data from each part of the lifecycle. In many cases this data was lacking, event hough great effort was made to collect it. Another important aspect is the balance between different aspects of sustainability within decision-making. Social implications are currently insufficiently presented in circular economy related literature, which is mostly dominated by environmental aspects (Merli et al., 2018). 

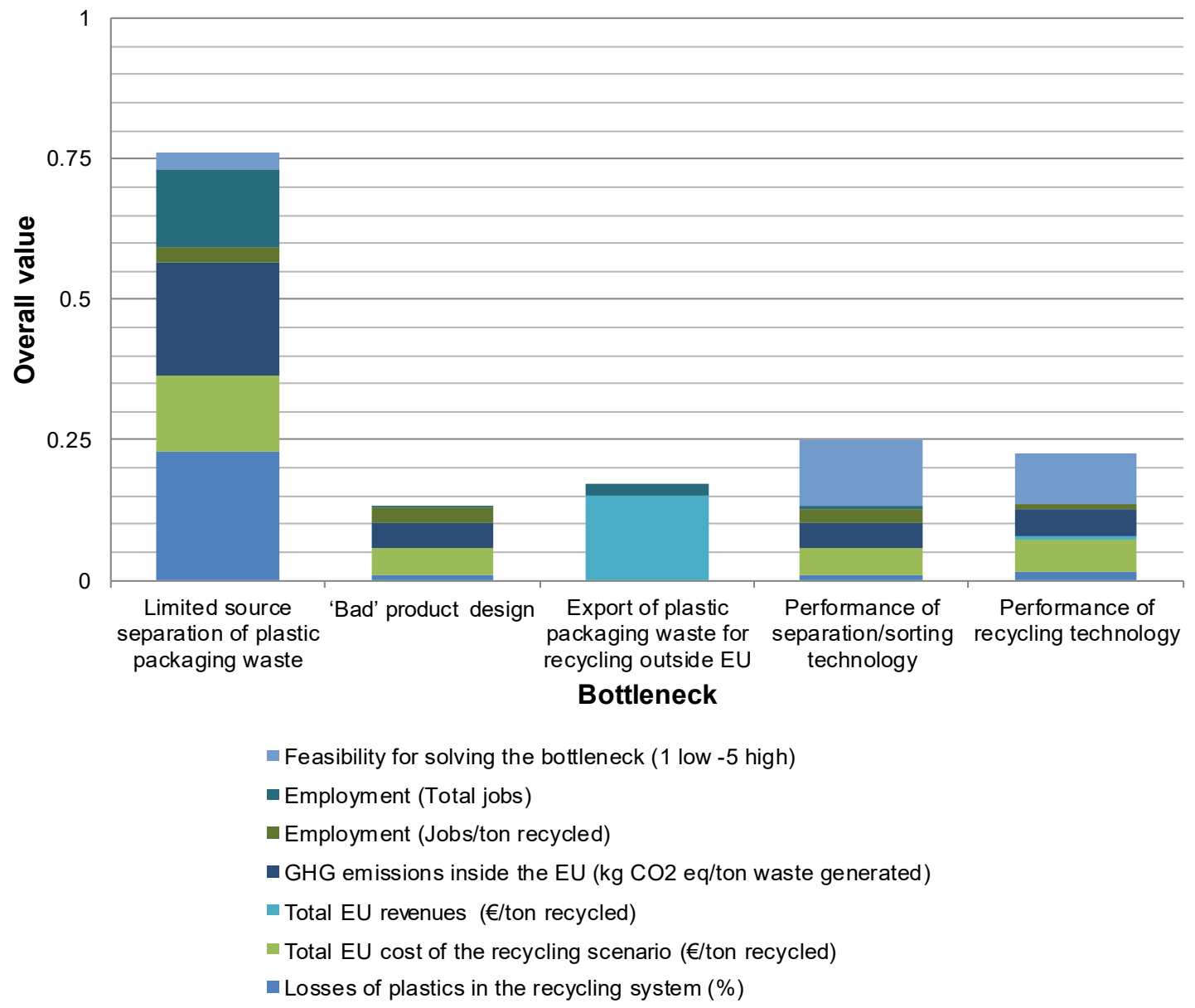

FIGURE 5: The results from MCDM in the PPW chain. Adapted from (Bacher et al., 2016).

Group MCDM methods may be helpful in addressing this shortage, since they in principle allow inclusion of economic, social and environmental criteria within the same decision-making context, although this might be challenging to apply in practice.

The findings from the case study highlight that transparent statistics and better information on the material flows within the value chains would be essential for successful use of the MCDM methods, and for advancing circular economy and related research. This would require more efficient monitoring activities and development of uniform waste statistics across the EU, together with new technological solutions that would allow tracking certain materials along their lifecycle. Ideally, addressing decision-making situations typical for the circular economy (covering the product lifecycle and including environmental, economic and social criteria), would require flexible methods capable of addressing both quantitative and qualitative data, and data of different quality. Similar findings have been obtained earlier by Kangas et al., (2001) when evaluating the potential of alternative MCDM methods for increasing consensus building among participants (in the context of forest management). Methods that allow using both low and high quality information in the same problem enable better use of all information that is available and enable more thorough decision support (Kangas et al., 2001).
Despite the challenging premises for decision-making faced at the EPWs, the participating experts considered the exercise and related discussions useful and interesting. Having participants with different backgrounds enabled addressing differing viewpoints while still trying to reach consensus. For example, while trade-off comparisons of criteria performances were perceived very difficult, the DMs became more comfortable after the first individual preference elicitations. The discussions within the group continued through the elicitation process. Once all preferences were elicited, the decision-makers felt satisfied with the results. This might have been assisted by two factors: the decision-makers were reassured by the discussions on their preferences, and the views on the meaningfulness of the criteria (based on data availability, limited scope etc.) were also shared by the participants.

\subsection{Limitations of the study}

The observations are based on a small sample of two empirical group MCDM exercises. There were differences in the composition of the expert panels but since the aim of this study was not to compare the results from the two workshops, this was not considered problematic. Furthermore, the participants in both expert panels represented a heterogenous group of stakeholders and thus differing points of view could be integrated in the process. Limita- 


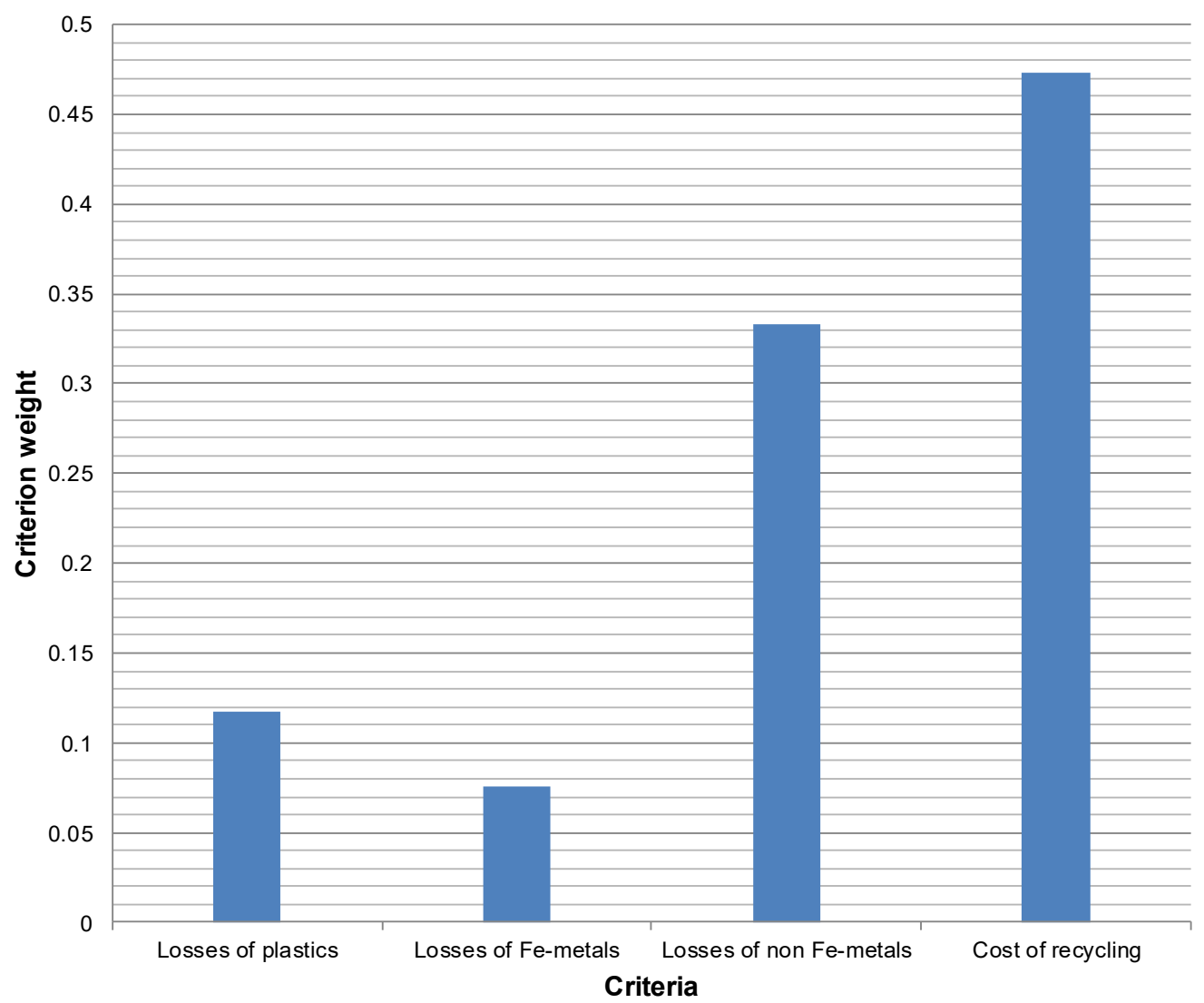

FIGURE 6: The criteria weights in the ELV chain. Adapted from (Bacher et al., 2016)

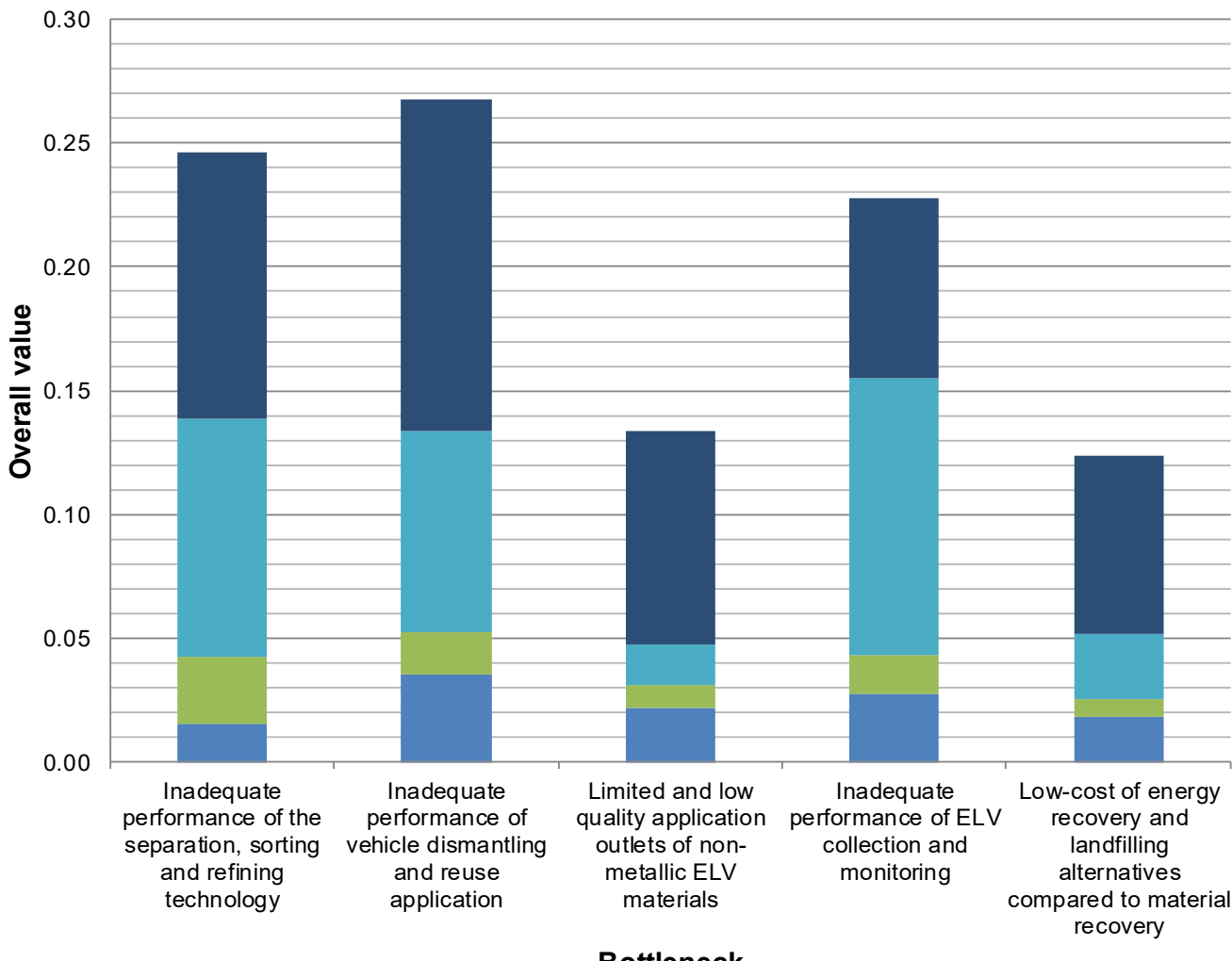

Bottleneck

- Losses of plastics $\quad$ Losses of Fe-metals $\quad$ Losses of non Fe-metals $\quad$ Cost of recycling

FIGURE 7: The results from the MCDM in the ELV chain. Adapted from (Bacher et al., 2016). 
tions in availability of background data and ability to measure the impacts of some of the bottlenecks in quantitative terms resulted in reducing the number of bottlenecks and criteria that could be applied in the case study. While this can be considered as a limitation of the process, it simultaneously allowed analys of the challenges that can be faced in such a case study. Even with a reduced number of criteria and bottlenecks, the applicability of the methods could be tested. Most importantly, the participating stakeholders considered the process interesting and useful.

Using AHP allowed capitalizing on expert judgement in substituting for the lack of performance data of the alternatives in the selected criteria. In addition to evident issues on confidence in the results, such a decision-making process requires a considerable amount of time and is highly dependent on the selected expert group. Furthermore, the burdensome task in the empirical MCDM required leaving out the social and environmental criteria, other than material losses, which are all central to advancing the circular economy. As each alternative had to be contested against each other in fulfilling each criterion, also the number of alternatives were needed to be kept to a minimum in the empirical setting, thus affecting the results of the bottleneck prioritization.

Similarly, as comparable data is needed for all alternatives for each criterion using MAVT, the unavoidable shortcomings in data availability result in the rejection of criteria and alternatives prior to decision-making. This can lead to reduced transparency in the problem setting and the results. As a consequence, if the methods were applied in a real-life context, e.g. for prioritizing policy actions or implementation alternatives, considerable efforts would need to be dedicated to data collection and impact evaluation prior to the actual decision-making situation.

A methodological limitation to both MCDM cases was the use of linear value functions due to practical limitations. In other words, the non-linearities in the decision-makers' preferences over changes in the criteria performances of alternatives were not elicited. Regarding alternative approaches to AHP or MAVT, popular outranking methods, such as PROMETHEE (Brans et al., 1986) were not assessed. Application of these MCDM methods to group decision-making within CE remains an interesting subject for more research. Consideration of the generally known risks for shortcomings of the MCDM methodologies such as rank-reversals on the addition or removal of an alternative in AHP (Wang and Elhag, 2006) were left outside the scope of this study.

\section{CONCLUSIONS AND RECOMMENDATIONS}

The aim of the paper was to evaluate the potential of structured group decision-making methods to support co-operation between stakeholders and create learning that would be necessary in order to tackle the bottlenecks in the recycling value chains. The applicability of two different MCDM methods, AHP and MAVT, was tested for prioritizing bottlenecks in the PPW and ELV value chains. The empricial case study was limited in scope but learnings from the case study provide findings that could be of inter- est to the circular economy research community, and also for future policy development. While both MCDM methods and the circular economy have been extensively studied before, our understanding is that group decision-making methods have not yet been used in the context of circular economy studies. Thus the main contribution of this paper lies in combining these two approaches.

The experiences gained during the case study, together with the findings from the MCDM literature (see e.g. Kiker et al., 2005; Van den Hove 2006; Soltani et al., 2015) point out that structured group decision-making methods could be an effective means to increase co-operation and integrate views of different actors. In addition, they could promote openness of information and trust between actors in the value chain.

In the future, group decision-making methods could be applied as participatory methods to enable the collection and integration of stakeholder views within circular economy policy development and implementation activities. However, efficient use of the MCDM methods requires tackling some of the method-related challenges that include, for example, demands related to background data and criteria definition. Additionally, inclusion of qualitative data and criteria should be possible, in order to address different elements of the circular economy (environment, economy and society). This will also require that enough resources (time and money) are available to collect necessary background information and conduct the evaluations.

In order to support consensus-building, then applied methods should be capable of integrating the views of a large group of stakeholders, possibly having very different perspectives and backgrounds for evaluating the decision-making problem under study. Since the circular economy covers full product lifecycles, participating experts should represent all parts of the lifecycle, as well as different businesses, authorities, end-users and academia. This might be difficult to handle in practice, and will require commitment from the participating stakeholders. However, bringing together several actors from a supply chain (creating a life cycle view) is an essential element of the circular economy. The number of studies addressing whole supply chains in the circular economy is still limited (see Merli et al., 2018) and thus more research is needed on this topic in the future.

An important contribution from the use of group decision methods should be knowledge exchange and discussion among the participants. This is important since information exchange has been recognized as one of the major constraints to the success or circular economy initiatives (Winans et al., 2017). Structured group decision-making methods provide occasions for people with various backgrounds to exchange their views and learn how other persons think and what they consider important. Thus, in addition to creating a priority order for decision attributes and available alternatives, understanding the views of others may help us in understanding the impacts of our own actions within the value chain. 


\section{ACKNOWLEDGEMENTS}

The authors would like to thank all partners of the New InnoNet project and participants of the two expert workshops for their contributions to the bottleneck analysis and MCDM exercises. New_InnoNet received funding from the European Union's Horizon 2020 research and innovation programme under grant agreement no 642231.

A concise version of the study has been presented in the proceedings of the Sardinia 2017 - 16th International Waste Management and Landfill Symposium.

\section{REFERENCES}

Andersson, M., Ljunggren Söderman, M., and Sandén, B. A. (2017a). Are scarce metals in cars functionally recycled? Waste Management, 60, 407-416. https://doi.org/10.1016/j.wasman.2016.06.031

Andersson, M., Ljunggren Söderman, M., and A. Sandén, B. (2017b). Lessons from a century of innovating car recycling value chains. Environmental Innovation and Societal Transitions. https://doi. org/10.1016/j.eist.2017.03.001

Bacher, J., Pihkola, H., Kujanpää, L., Mroueh, U.-M., Vanderreydt, I., and Garcia Zambrano, L. (2016). Bottleneck analysis of WEEE, ELV and Plastics packaging chains: key findings and commonalities. Retrieved from http://www.newinnonet.eu/downloads/D2.5 Bottleneck_analysis_key_findings_and_commonalities.pdf

Brans, J. P., Vincke, P., and Mareschal, B. (1986). How to select and how to rank projects: The Promethee method. European Journal of Operational Research, 24(2), 228-238.

da Cruz, N. F., Ferreira, S., Cabral, M., Simões, P., and Marques, R. C. (2014). Packaging waste recycling in Europe: Is the industry paying for it? Waste Management, 34(2), 298-308. https://doi. org/10.1016/J.WASMAN.2013.10.035

Dahlbo, H., Poliakova, V., Mylläri, V., Sahimaa, O., and Anderson, R. (2018). Recycling potential of post-consumer plastic packaging waste in Finland. Waste Management, 71, 52-61. https://doi. org/10.1016/J.WASMAN.2017.10.033

de Jesus, A., and Mendonça, S. (2018). Lost in Transition? Drivers and Barriers in the Eco-innovation Road to the Circular Economy. Ecological Economics, 145(July 2017), 75-89. https://doi. org/10.1016/j.ecolecon.2017.08.001

DIRECTIVE 2000/53/EC OF THE EUROPEAN PARLIAMENT AND OF THE COUNCIL of 18 September 2000 on end-of life vehicles. (2000). Retrieved from http://eur-lex.europa.eu/legal-content/EN/TXT/PDF/? uri=CELEX:02000L0053-20130611 andqid $=1405610569066$ andfrom $=E N$

Dyer, J. S., and Sarin, R. K. (1979). Measurable Multiattribute Value Functions. Operations Research, 27(4), 810-822. https://doi. org/10.1287/opre.27.4.810

European_Commission. (2015). An EU action plan for the circular economy. Com, 614, 21. https://doi.org/10.1017/ CB09781107415324.004

EUROPEAN PARLIAMENT AND COUNCIL DIRECTIVE 94/62/EC of 20 December 1994 on packaging and packaging waste. (1994). Retrieved from http://eur-lex.europa.eu/legal-content/EN/TXT/ PDF/?uri=CELEX:01994L0062-20150526andfrom=EN

Eurostat. (2018a). End-of-life vehicle statistics. Retrieved April 18 2018, from http://ec.europa.eu/eurostat/statistics-explained/ index.php/End-of-life_vehicle_statistics\#Database

Eurostat. (2018b). Packaging waste statistics. Retrieved April 18, 2018 from http://ec.europa.eu/eurostat/statistics-explained/index.php/ Packaging_waste_statistics

Geyer, R., Jambeck, J. R., and Law, K. L. (2017). Production, use, and fate of all plastics ever made. Science Advances, 3(7), e1700782. https://doi.org/10.1126/sciadv.1700782

Goulart Coelho, L. M., Lange, L. C., and Coelho, H. M. (2017). Multi-criteria decision making to support waste management: A critical review of current practices and methods. Waste Management and Research, 35(1), 3-28. https://doi.org/10.1177/0734242X16664024

Groot, J., Bing, X., Bos-Brouwers, H., and Bloemhof-Ruwaard, J. (2014). A comprehensive waste collection cost model applied to post-consumer plastic packaging waste. Resources, Conservation and Recycling, 85, 79-87. https://doi.org/10.1016/J.RESCONREC.2013.10.019
Hahladakis, J. N., Purnell, P., lacovidou, E., Velis, C. A., and Atseyinku, M. (2018). Post-consumer plastic packaging waste in England: Assessing the yield of multiple collection-recycling schemes. Waste Management. https://doi.org/10.1016/J.WASMAN.2018.02.009

Inghels, D., Dullaert, W., Raa, B., and Walther, G. (2016). Influence of composition, amount and life span of passenger cars on endof-life vehicles waste in Belgium: A system dynamics approach. Transportation Research Part A: Policy and Practice, 91, 80-104. https://doi.org/10.1016/J.TRA.2016.06.005

Kangas, J., Kangas, A., Leskinen, P., and Pykäläinen, J. (2001). MCDM methods in strategic planning of forestry on state-owned lands in Finland: applications and experiences. Journal of Multi-Criteria Decision Analysis, 10(5), 257-271. https://doi.org/10.1002/ mcda.306

Keeney, R. ., and Raiffa, H. (1994). Decisions with multiple objectives-preferences and value tradeoffs. Behavioral Science. Cambridge : John Wiley and Sons, Ltd. https://doi.org/10.1002/ bs.3830390206

Kiker, G. A., Bridges, T. S., Varghese, A., Seager, T. P., and Linkov, I. (2005). Application of Multicriteria Decision Analysis in Environmental Decision Making. Integrated Environmental Assessment and Management, 1(2), 95. https://doi.org/10.1897/ IEAM_2004a-015.1

Mahpour, A. (2018). Prioritizing barriers to adopt circular economy in construction and demolition waste management. Resources, Conservation and Recycling, 134(January), 216-227. https://doi. org/10.1016/j.resconrec.2018.01.026

Merli, R., Preziosi, M., and Acampora, A. (2018). How do scholars approach the circular economy? A systematic literature review. Journal of Cleaner Production. https://doi.org/10.1016/j.jclepro.2017.12.112

Monier, V., Hestin, M., Cavé, J., Laureysens, I., Watkins, E., Reisinger, H., and Porsch, L. (2014). Development of Guidance on Extended Producer Responsibility (EPR). Retrieved from http://ec.europa. eu/environment/waste/pdf/target_review/Guidance on EPR - Final Report.pdf

Morrissey, A. ., and Browne, J. (2004). Waste management models and their application to sustainable waste management. Waste Management, 24(3), 297-308. https://doi.org/10.1016/j.wasman.2003.09.005

Preston, F. (2012). Briefing Paper - A Global Redesign? Shaping the Circular Economy. Chatham House. Energy, Environment and Resource Governance.

Rizos, V., Behrens, A., Kafyeke, T., Hirschnitz-Garbers, M., Ioannou, A. (2015). The Circular Economy: Barriers and Opportunities for SMEs (CEPS Working Documents). Retrieved from https://ssrn. com/abstract $=2664489$

Rousis, K., Moustakas, K., Malamis, S., Papadopoulos, A., and Loizidou, M. (2008). Multi-criteria analysis for the determination of the best WEEE management scenario in Cyprus. Waste Management, 28(10), 1941-1954. https://doi.org/10.1016/j.wasman.2007.12.001

Saaty, T. L. (1980). How to make a decision: the analytic hierarchy process. European Journal of Operational Research, 48(1), 9-26.

Seppälä, J., Basson, L., and Norris, G. A. (2002). Decision Analysis Frameworks for Life-Cycle Impact Assessment. Journal of Industrial Ecology, 5(4), 45-68. https://doi.org/10.1162/10881980160084033

Shen, L., and Worrell, E. (2014). Plastic Recycling. In E. Worrell and M. Reuter (Eds.), Handbook of Recycling (pp. 179-190). Elsevier. https://doi.org/10.1016/B978-0-12-396459-5.00013-1

Soltani, A., Hewage, K., Reza, B., and Sadiq, R. (2015). Multiple stakeholders in multi-criteria decision-making in the context of Municipal Solid Waste Management: A review. Waste Management, 35, 318-328. https://doi.org/10.1016/j.wasman.2014.09.010

Soo, V. K., Peeters, J., Compston, P., Doolan, M., and Duflou, J. R. (2017). Comparative Study of End-of-Life Vehicle Recycling in Australia and Belgium. Procedia CIRP, 61, 269-274. https://doi. org/10.1016/j.procir.2016.11.222

Van Beukering, P., Kuik, O., and Oosterhuis, F. (2014). The Economics of Recycling. In E. Worrel and M. Reuter (Eds.), Handbook of Recycling (pp. 479-489). Elsevier. https://doi.org/10.1016/B978-0-12396459-5.00031-3 
Van den Hove, S. (2006). Between consensus and compromise: acknowledging the negotiation dimension in participatory approaches. Land Use Policy, 23(1), 10-17. https://doi. org/10.1016/j.landusepol.2004.09.001

Vanner, R., Bicket, M., Withana, S., ten Brink, P., Razzini, P., van Dijl, E., Watkins, E., Hestin, M., Tan, A., Guilcher, S., Hudson, C. (2014). No TiScoping Study to Identify Potential Circular Economy Actions, Priority Sectors, Material Flows and Value Chains (DG Environment's Framework Contract for Economic Analysis ENV.F.1/ FRA/2010/0044 No. Final Report)tle.

Wang, Y.-M., and Elhag, T. M. S. (2006). An approach to avoiding rank reversal in AHP. Decision Support Systems, 42(3), 1474-1480. https://doi.org/10.1016/J.DSS.2005.12.002
Winans, K., Kendall, A., and Deng, H. (2017). The history and current applications of the circular economy concept. Renewable and Sustainable Energy Reviews, 68(August 2016), 825-833. https://doi. org/10.1016/j.rser.2016.09.123

Worrell, E. (2014). Recycling of Packaging. In E. Worrell and M. Reuter (Eds.), Handbook of Recycling (pp. 297-306). Elsevier. https://doi. org/10.1016/B978-0-12-396459-5.00021-0

Zhao, H., Zhao, H., and Guo, S. (2017). Evaluating the comprehensive benefit of eco-industrial parks by employing multi-criteria decision making approach for circular economy. Journal of Cleaner Production, 142, 2262-2276. https://doi.org/10.1016/j.jclepro.2016.11.041 